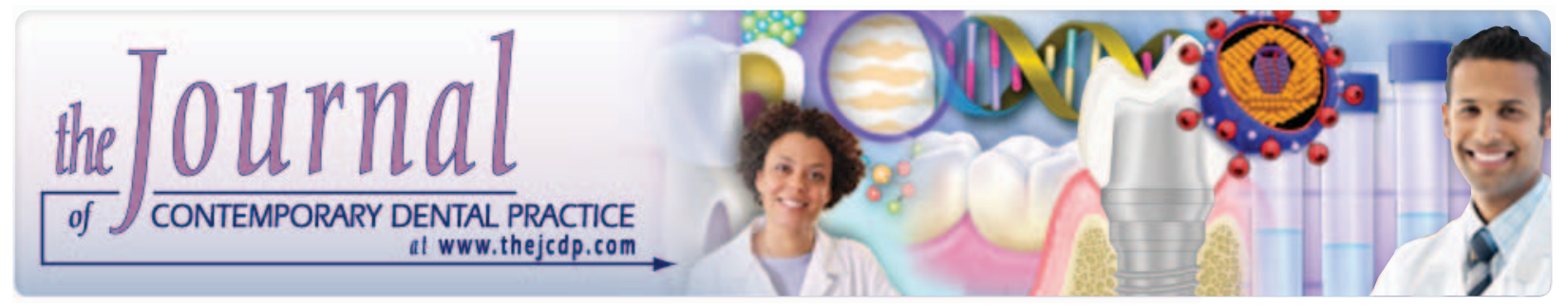

\title{
A New Concept in Restorative Dentistry: LIFEDT- Light-Induced Fluorescence Evaluator for Diagnosis and Treatment: Part 2 - Treatment of Dentinal Caries
}

Elodie Terrer, DDS; Anne Raskin, DDS, MS, PhD; Stephen Koubi, DDS; Alexandro Dionne; Gauthier Weisrock, DDS; Caroline Sarraquigne; Alain Mazuir; Hervé Tassery, DDS, MS, PhD

\begin{abstract}
Aim: A new and innovative therapeutic concept using a light-induced fluorescence evaluator for diagnosis and treatment (LIFEDT) of dental caries based on the imaging and autofluorescence of dental tissues is proposed. The aims of this series of in vivo experiments are to compare and analyze the brightness variations of sound dentin and active and arrested carious dentin illuminated with an intraoral LED camera and to determine if this new device could be helpful in daily practice to discriminate between caries and sound dentin.
\end{abstract}

Methods and Materials: A new intraoral LED camera that emits visible blue light was used in this in vivo study to illuminate and photograph 15 teeth at high magnification. The magnified images were examined using the free Image $\mathrm{J} \mathrm{V}^{\otimes}$ version 1.41 software. Four standardized rectangular areas were drawn on each picture that included both healthy and pathologic areas to analyze variations in brightness using a brightness formula: $L^{*}=0.299$ Red + 0.587 Green + 0.114 Blue.

Results: Statistically significant differences in the brightness were found between active and arrested caries processes in an area of infected dentin designated Z2. Within the limitations of this in vivo study, the images created with the intraoral LED camera revealed significant variations in fluorescence between sound dentin and active and arrested caries processes.

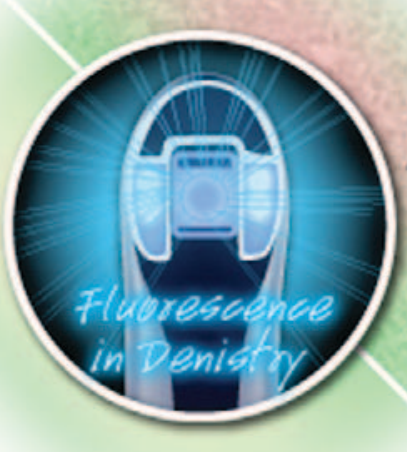

Conclusions: The LIFEDT concept provides a therapeutic concept based on these findings of variations in fluorescence between healthy and pathologic tissue.

Clinical Significance: This concept defines a pragmatic clinical and therapeutic approach for treating active and arrested carious lesions based on the interpretation of variations of a fluorescence signal and applying the LIFEDT concept to the treatment of dentin carious lesions.

Keywords: Active caries, arrested caries, dentin fluorescence, caries discrimination, LED camera.

Citation: Terrer E, Raskin A, Koubi S, Dionne A, 
Weisrock G, Sarraquigne C, Mazuir A, Tassery H. A New Concept in Restorative Dentistry: LIFEDT-Light-Induced Fluorescence Evaluator for Diagnosis and Treatment: Part 2 - Treatment of Dentinal Caries. J Contemp Dent Pract [Internet]. 2010 Jan; 11(1):095-102. Available from: http://www.thejcdp.com/journal/view/ volume11-issue1-terrer.

\section{Introduction}

In Part 1 of this two-part series, ${ }^{1}$ the focus was on the diagnostic potential of the images generated with a new intraoral LED camera. Two decision-making diagrams were proposed in that article based on images observed, while referring to international recommendations. ${ }^{2-4}$ The principle employed was to analyze variations in fluorescence of a clinically suspicious carious area in relation to the fluorescence of a healthy area on the same tooth.

Experimentation using the same imaging technology has continued into the treatment phase, i.e., after cavity preparation to remove the carious lesion. In this specific scenario, several caries detection tools are available to discriminate between healthy and carious dentin either in vivo or in vitro with more or less success in terms of sensitivity or specificity. ${ }^{\frac{5-9}{}}$ These detection tools include the following:

- $\mathrm{FACE}^{5}$ (fluorescence-aided caries excavation)

- DIFOTI (digital imaging fiber-optic transillumination)

- $\mathrm{QLF}^{6}$ (quantitative light fluorescence)

- FC (VistaProof, Dürr Dental, BietingenBissingen, Germany) ${ }^{7}$

- DIAGNOdent (laser)

Other strategies for this purpose involve the use of multiphoton imaging, infrared thermography, infrared fluorescence, optical coherence tomography, ultrasound, and terahertz imaging. Nevertheless, the "take it or leave it" approach, as expressed by Banerjee et al., ${ }^{10}$ is still utilized. Clinicians continue to be confronted with how to identify carious tissue and where to stop the caries excavation process. ${ }^{10}$ The inherent problem with existing clinical criteria (hardness, color, and penetration of caries dyes) is a lack of standardization and clinical subjectivity. ${ }^{10}$ Recent studies ${ }^{11}$ based on the CIE 1976 L*a*b* $^{*}$ color system stipulated that brightness ( $\left.L^{*} v a l u e\right)$

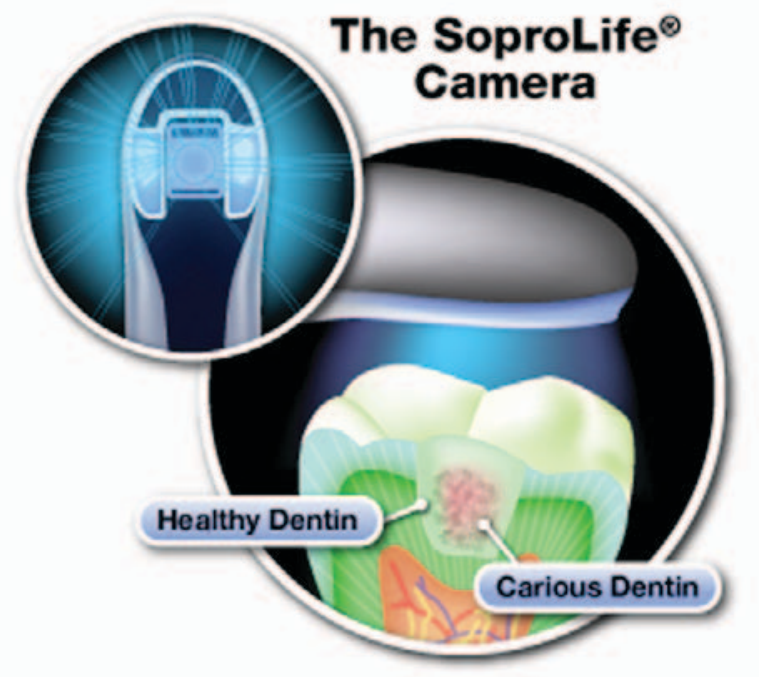

decreased as the rate of bacterial detection increased and that the $L^{*}$ value was related to the degree of caries progression. Hence, the aims of the series of experiments in the present study were to:

1. Compare and analyze the brightness variations $\left(L^{*}\right)$ of sound and carious dentin illuminated with an intraoral LED camera emitting visible blue light without prior distinction of the type of caries process (active or arrested) or brightness variations of dentin within a representative RGB model space.

2. Determine if this new device could be helpful in current practice based on interpretation of the fluorescence signal variation observed.

3. Apply the LIFEDT ${ }^{1}$ concept to the treatment of dentinal carious lesions based on images and fluorescence variations observed.

The null hypothesis tested was that the fluorescence of carious dentin, illuminated with the new intraoral LED camera, does not vary between sound dentin and either active or arrested dental caries.

\section{Methods and Materials}

This study was designed based on the Patient (or Problem), Intervention, Comparator, and Outcome (PICO) question formulation process, $\frac{12,13}{}$ as described below.

\section{Patients (P)}

Fifteen teeth among 15 patients with active or arrested caries processes, and with no prior 
distinctions, were selected for the study. The stage of each caries process was evaluated using an oral bitewing dental radiograph (Kodak, Rochester, NY, USA) developed in an automatic film processor (Durr Dental System, BietigheimBissingen, Germany). The duration of the study was six months. All patients were recruited at the Centre Gaston Berger, Marseille Dental School, France, and the University of the Mediterranean. All patients were informed in advance of the aim of this trial and signed an approved consent form.

The inclusion criteria were as follows:

- Patient age minimum of 18 years old

- Existence of average to good oral hygiene

- Presence of developing caries at the molar or premolar sites 1, 2 and 3 within lesion sizes 1, 2 and $3^{14}$

The exclusion criteria include those patients with irreversible pulp disease or patients in dental emergency status.

\section{Intervention (I)}

The dental treatment steps used in the study were as follows:

1. A dental dam (Dentaldam ${ }^{\circledR}$, Bisco, Schaumburg, IL, USA) was placed and the carious lesion was excavated using a hand excavator $\mathrm{EXC18H}$ (Hu-Freidy ${ }^{\circledR}$, Chicago, IL, USA).

2. A hybrid glass ionomer (Cavity Conditioner ${ }^{\circledR}$ and Fuji II.LC ${ }^{\circledR}$, GC, Tokyo, Japan) was injected into the cavity preparation as a base material.

3. A nanohybrid dental composite (Adhese System $^{\circledast}$ and Tetric EvoCeram ${ }^{\circledast}$ cured with a Blue Phase ${ }^{\circledR}$ LED curing light at $1200 \mathrm{~mW} / \mathrm{cm}^{2}$ (Vivadent, Schaan, Liechtenstein) was used to fill the cavity preparation.

For the image analysis, a picture was recorded with the intraoral LED camera at each of the three stages of the clinical procedure:

1. The tooth before preparation

2. The opened cavity

3. Completion of excavation using clinical criteria (color of residual dentin and hardness)

To avoid any interference with the fluorescence of the LED camera, no caries detector dyes were used in this experiment.

Detailed information about the LED camera is presented in Part I of this two-part series. ${ }^{1}$
In summary, the Acteon Imaging ${ }^{\circledast}$ (Sopro SA, La Ciotat, France) is a patented LED video camera that uses a visible blue light frequency to illuminate the surface of the teeth and provides an anatomic image overlay onto the fluorescent image emitted by the teeth. The illumination occurs at a wavelength of $450 \mathrm{~nm}$ with a bandwidth of $20 \mathrm{~nm}$, centered at $\pm 10 \mathrm{~nm}$ around the excitation wavelength. The camera is equipped with an image sensor (a 0.25-inch CCD sensor) consisting of a mosaic of pixels covered with filters of complementary colors. These filters have a greater range of reaction across the light spectrum, compared to the primary colors (RGB).

\section{Comparison (C)}

The basic principle of observation and calibration used in this study was to observe consistent variation in the carious dentinal tissue fluorescence/ brightness in relation to a healthy area.

Digital photographs of the teeth in the study were taken systematically at the highest magnification (30x) with the LED camera. Images were then transferred to a computer using the SOPRO ${ }^{\circledR}$ software (Sopro Imaging ${ }^{\circledR}$, Sopro SA, La Ciotat, France) and analyzed using the free Image $\mathrm{J}$ V.1.41 software ${ }^{\circledR}$ (image processing and analysis in Java, Bethesda, MD, USA). Four standardized rectangular areas were drawn $(10 \mathrm{~mm}$ long by 10 $\mathrm{mm}$ wide) on each picture ( $150 \mathrm{~mm}$ long by 120 $\mathrm{mm}$ wide) and labeled as follows:

- Z1, a healthy area of the tooth (Figures 1 and 3)

- Z2 and Z3 (Figures 1 and 3), before excavation

- Z4, in an open area at the end of excavation (Figures 2 and 4 )

Area Z2 was associated with infected dentin, Z3 with the infected/affected dentin structure, and Z4 with the affected dentin (end of excavation).

Four levels of brightness $\left(L^{*}\right)$ for each section were obtained and compared: $L^{*}=0.299$ Red +0.587 Green +0.114 Blue, which were transformed in the RGB color space as L* green, L*red, and L*blue. For each area, the mean and standard deviation of the brightness values were recorded. As for the caries process, the active or arrested status was only determined in teeth with an open cavity.

\section{Outcome (0)}

The expected outcome was this new technology 


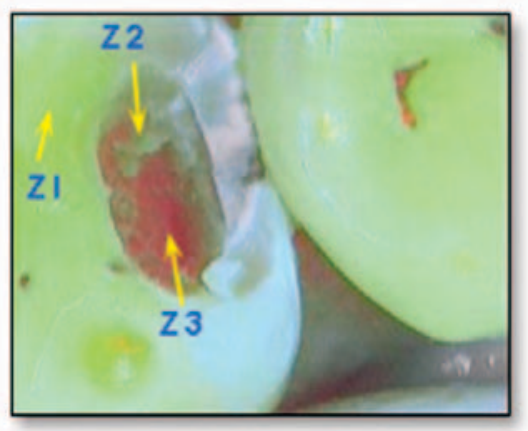

Figure 1. View of the fluorescence of dentin with the cavity opened. Areas (10 mm long by $10 \mathrm{~mm}$ wide) are Z1, healthy; Z2, infected; and Z3, infected/affected in an active caries process.

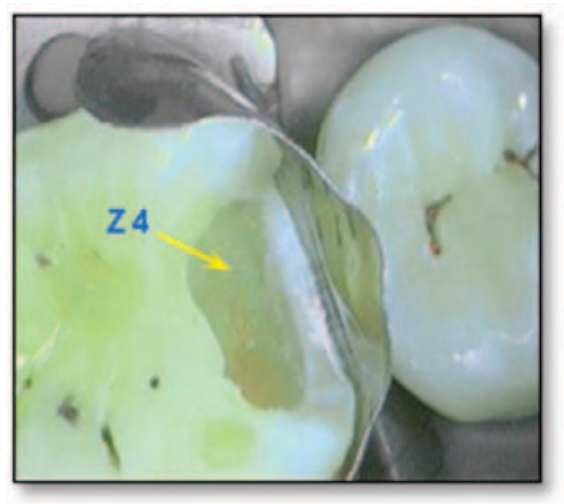

Figure 2. Fluorescence of active caries process at the end of excavation: Z4, end of excavation area $(10 \mathrm{~mm}$ long by $10 \mathrm{~mm}$ wide).

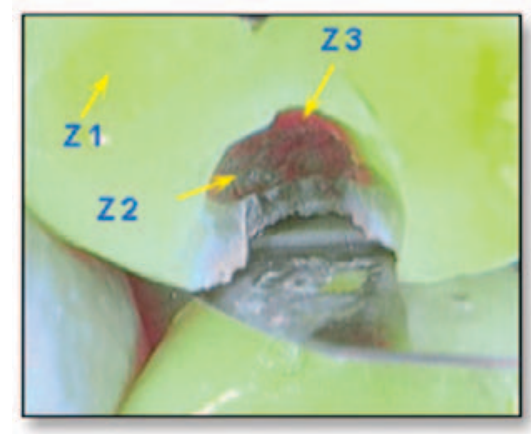

Figure 3. Fluorescence of dentin, cavity opened. Areas ( $10 \mathrm{~mm}$ long by $10 \mathrm{~mm}$ wide) are $\mathbf{Z 1}$, healthy; $\mathbf{Z 2}$, infected; and Z3, infected/affected arrested caries process.

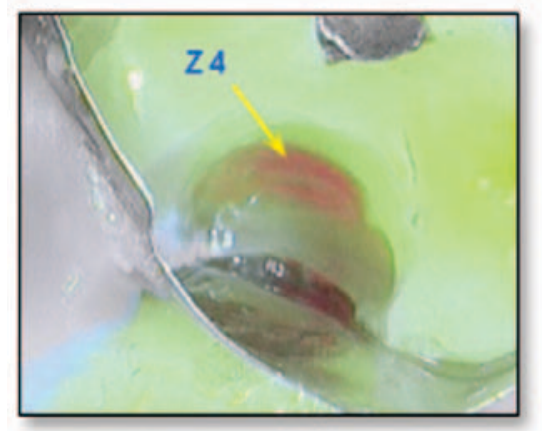

Figure 4. Fluorescence of an arrested caries process at the end of excavation: $\mathbf{Z 4}$, at the end of the excavation area (10 $\mathrm{mm}$ long by $10 \mathrm{~mm}$ wide).

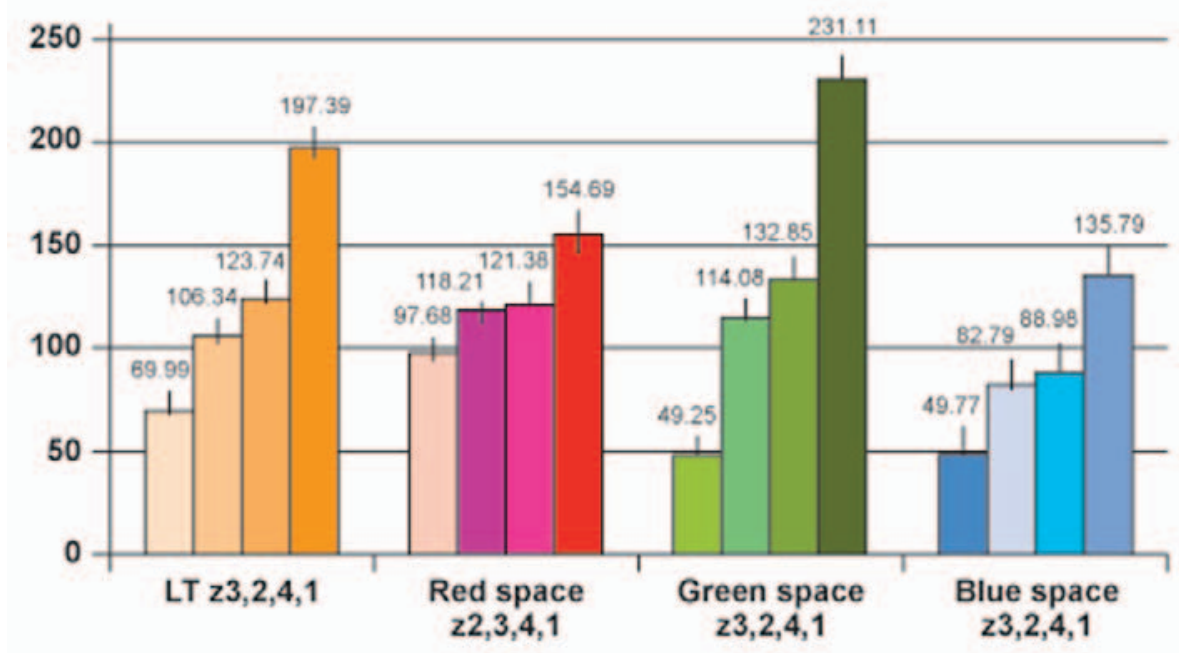

Figure 5. Total brightness (LT) of the four areas and in the red, green, and blue space respectively, independent of the type of carious lesion (mean value). Vertical bars $=$ standard deviation . 


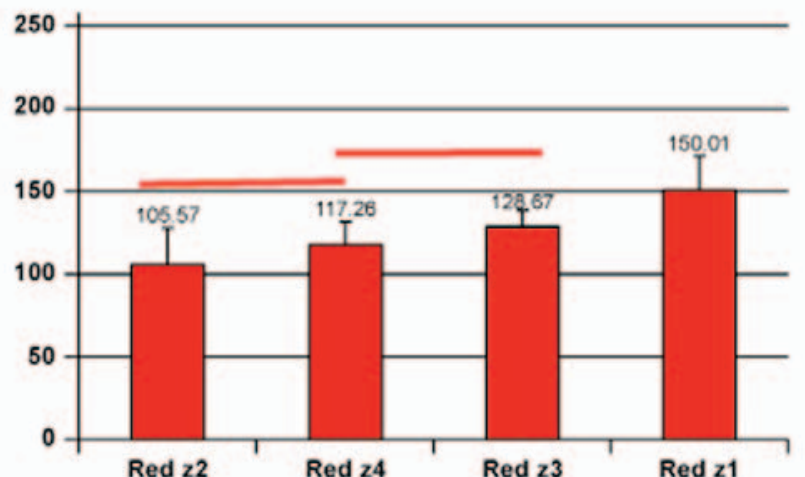

A. $L^{*}$ brightness in the red space. Active caries.

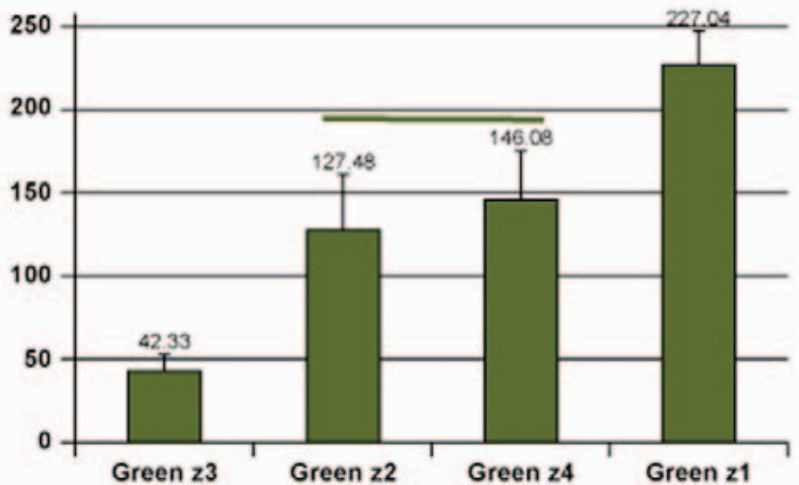

C. $L^{*}$ brightness in the green space. Active caries

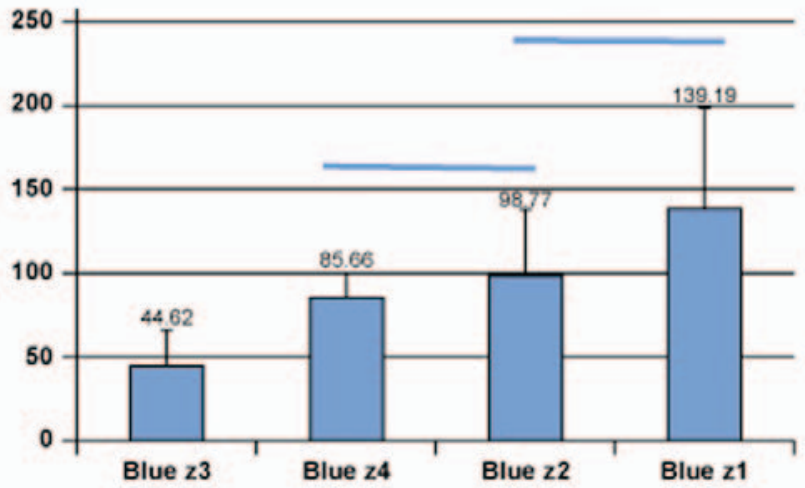

E. $L^{*}$ brightness in the blue space. Active caries.

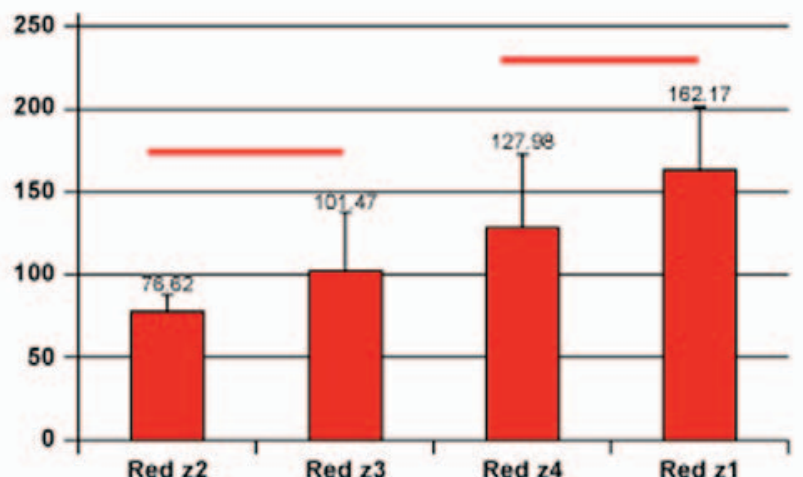

B. $L^{*}$ brightness in the red space. Arrested caries.

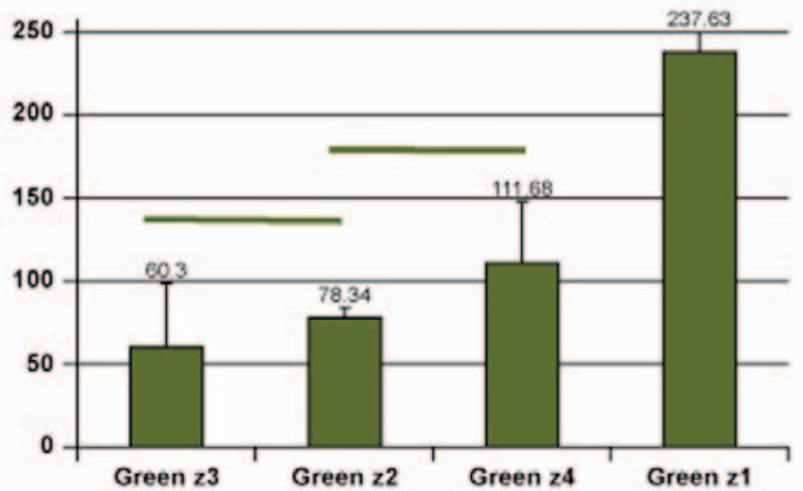

D. $L^{*}$ brightness in the green space. Arrested caries

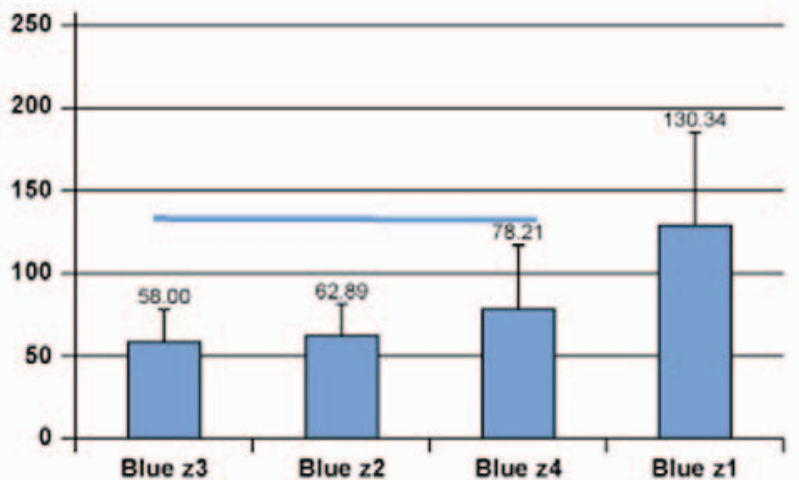

F. L* brightness in the blue space. Arrested caries.

Figure 6. $L^{*}$ brightness variations in the red $(A$ and $B)$, green $(C$ and $D)$, and blue ( $E$ and F) RGB space in active and arrested caries processes, respectively (mean values). Graphs with a horizontal line to link vertical bars did not differ statistically.

would be a reliable aid to clinicians in

discriminating and excavating carious dentin.

\section{Statistical Analysis}

The Mann-Whitney $U$ and the Wilcoxon signedrank tests were used for statistical analysis. ${ }^{15}$ The Wilcoxon signed-rank test was used to compare the total brightness and the brightness in the red, green, and blue RGB space between the four different defined areas of the teeth (Z1 to Z4) for the overall experimental group (Figure 5) and then for active caries and for arrested caries (Figure 6).

The Mann-Whitney $U$ test was used to compare active caries and arrested caries for the different parameters tested in the four different defined areas of the teeth (Figure 7). 


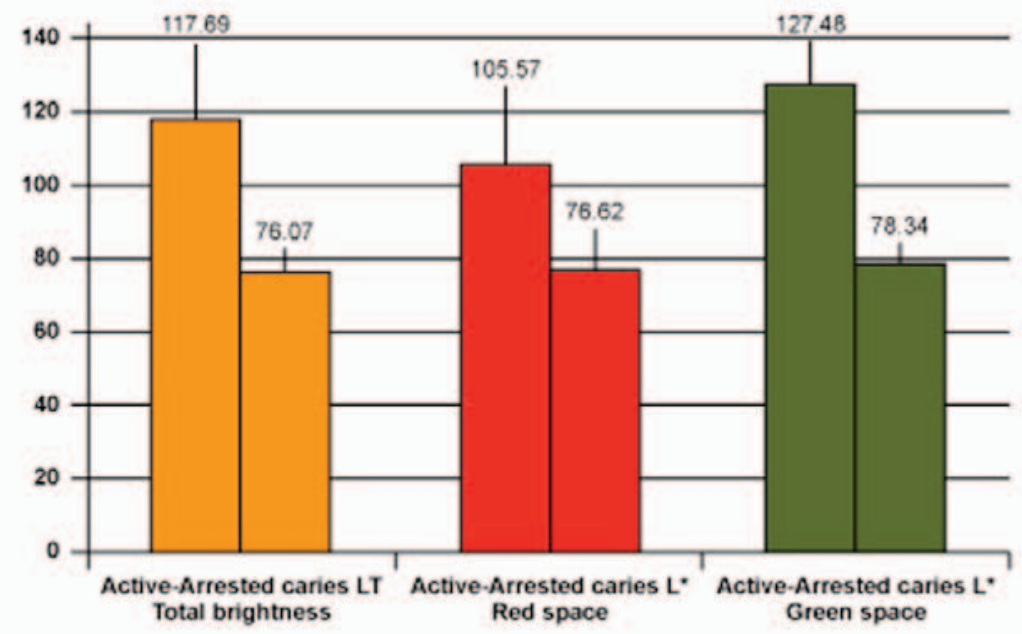

Figure 7. In the $Z 2$ section, total (LT) and $L^{*}$ brightness variations in the red and green RGB space of active versus arrested caries processes respectively (mean value).

\section{Results}

\section{Brightness Variations}

The brightness variations were analyzed taking into account the total brightness and the brightness in the red, green, and blue RGB space. The first analysis involved all types of caries processes (Figure 5), the second incorporated active and arrested caries processes (Figure 6), and the third focused on active versus arrested caries processes (Figure 7).

The total dentin brightness decreased from $\mathrm{Z} 1$ to $Z 3$ and then increased slightly at the end of the excavation (Z4). In the Z3 area using the red RGB space, the brightness increased and the drop in brightness variation decreased a second time. The values in areas $Z 2$ and $Z 3$ did not differ from those in area Z4. In the green RGB space, the brightness dramatically diminished then increased in area Z4. All of the LT and brightness values in the green space were different (Figure 5).

In the blue RGB space, the brightness dramatically diminished in area Z3 then increased in area Z4. The brightness values were the same for areas $Z 2$ and Z4. (Figure 5). In the red RGB space (Figure $6 \mathrm{~A}$ ), the $\mathrm{L}^{*}$ variations, even for the active and arrested caries processes, were more linear than in the green/blue space. The red $L^{*}$ slightly increased in the Z3 area (infected/affected level) in contrast to the green $L^{*}$, which showed the greatest drop (Figure 6C). The green delta values (areas Z1 to Z3) were approximately 185

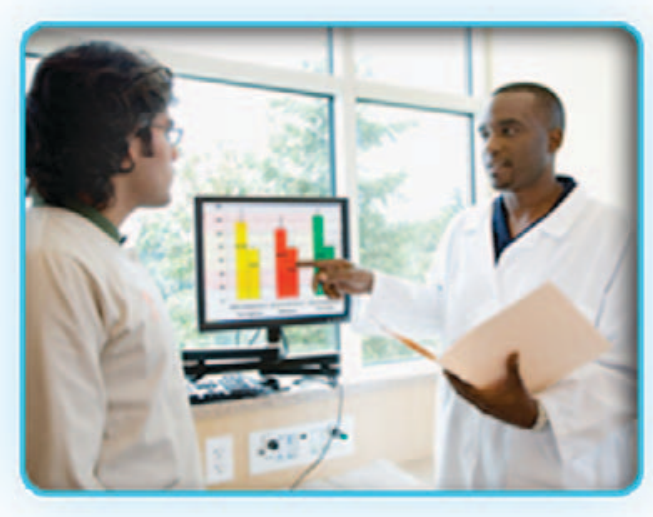

pixels in active caries processes and around 177 pixels in arrested caries. The same delta values in the red space were only 30 and 60 , respectively. In the blue space, the delta values (areas Z1 to Z3) were higher than in the red space but lower than in the green space (Figure 6E).

In a two-by-two comparison (Figure 7), statistical differences were only observed for the Z2 area (infected dentin) in two RGB spaces: red and green. In most cases, the brightness of arrested caries was lower than for active caries. Clinically, healthy area Z1 appeared bright green; however, in the presence of active caries, area Z2 was a dark-green color, area Z3 was bright red (Figure1), and area Z4 was gray-green, always less bright than area Z1. As for the arrested caries process (Figures 3 and 4), healthy area Z1 looked bright green, Z2 dark green, Z3 red, and Z4 slightly red, but all images were darker than 
images of the active caries process. For arrested or slow-progressing lesions, the persistence of saveable intra-tubular or peripulpal tertiary dentin generates a shadowy red fluorescent interface at the bottom of the cavity (Figure 4, arrow).

\section{Discussion}

The clinically relevant aspects of this experiment were as follows:

1. Active and arrested caries process areas ( $Z 1$, Z2, Z3, and Z4) looked different in terms of fluorescence and brightness.

2. Healthy dentin can also be clearly discriminated from carious dentin as it looks bright green ( $Z 1$ area; Figures1 and 3) at the highest level of brightness ( $\mathrm{Z1}$ areas in Figure 6A-F).

3. Any carious lesion could be detected by the variation in the fluorescence of its tissues in relation to a healthy area of the same tooth.

4. The objective of the LIFEDT concept is to adapt these observations in routine clinical practice.

Therefore, it is essential to analyze the brightness and fluorescence variations of dental tissue. In the active caries process, reparative dentin is synthesized mostly without dentinal tubules, in contrast to sclerotic dentin in arrested caries in which the dentinal tubules are full of mineralized deposits. These two types of dentin structure could partially account for the $L^{*}$ variations. The reason statistical differences were only observed for the Z2 area (infected dentin) in the red and green RGB space remains unclear. A more remarkable observation was the large drop in $L^{*}$ green in the presence of both active and arrested caries, which accounts for why the Z3 area looked red in active and arrested caries. One of either the organic or inorganic constituents of healthy dentin that emits an acid-green fluorescence partially disappears during the caries process; hence, the red fluorescence appears. Dentinal constituents emitting a red fluorescence seem to be less damaged by the caries process. The Maillard reaction (nonenzymatic browning reaction) with the generation of advanced Maillard products (carboxymethyllysine and pentoside) have been previously described in carious dentin. ${ }^{16}$ This phenomenon might partially account for fluorescence variations due to suspected fluorophores in carious dentin such as dityrosine, pentoside, and the Maillard reaction products.
The clinical decision to remove or leave suspicious dental tissue was made with the help of information provided by this new LED camera along with a visual examination. Unlike the VistaProof FC camera ${ }^{7}$ (Dürr Dental, Bietingen-Bissingen, Germany), the LED camera in the present study did not excite the bacterial fluorophore porphyrin in the wavelength between 670 and $700 \mathrm{~nm}$. A recent study ${ }^{7}$ that compared the performance of fluorescence-based methods (FC, DIAGNOdent, radiograph examination, and ICDAS II [International Caries Detection and Assessment System]) concluded that bitewing radiographs combined with an ICDAS II visual examination appears to be the best diagnostic combination to detect caries. Therefore, the judgment of the clinician would still appear to prevail in all cases.

The LED camera, unlike the DIAGNOdent (Kavo, Biberach, Germany), provides an overall image of the clinical situation instead of a point-bypoint measurement. The DIAGNOdent has been described as having a good level of sensitivity and low specificity, ${ }^{17,18}$ but it was more useful for caries diagnosis than for caries discrimination, and there were false-positive signals. Moreover, a recent study ${ }^{19}$ has revealed that measurements from DIAGNOdent were not strongly correlated with the depth and volume of the cavity preparation and concluded that appropriate visual examination training may provide similar results without the need for additional equipment.

The second aim of this study was to assess the suitability of using this device in daily practice. No prior distinction between the different caries processes was made because the present analysis was the first assessment of this new technology. Every effort was made to avoid introducing any bias into the interpretation of the images as a result of preconceptions. Within the limitations of the number of teeth in this study, the fluorescence of dentin in active and arrested states from Z3 and Z4 looked different enough to be discriminated with appropriate visual training. In the arrested area (Z4), a red shadow persisted at the bottom of the preparation in all cases (Figure 4). Based on the first results of this experiment and despite these limitations, the fluorescence variations between active and arrested caries led to the rejection of the null hypothesis. 
Table 1: The LIFEDT concept applied to treatment of dentinal caries.

\begin{tabular}{|c|c|}
\hline Principle & $\begin{array}{l}\text { First, analyze a healthy area on the tooth concerned for use as the fluorescence } \\
\text { reference during image processing and analysis. (Clinical case: Figure 8) }\end{array}$ \\
\hline \multirow{3}{*}{ Active Carious Lesion } & $\begin{array}{l}\text { Visual signals in fluorescent mode: } \\
\text { - Healthy dentin: acid green fluorescence. } \\
\text { - Infected dentin: green-black fluorescence. } \\
\text { - Infected/affected dentin: bright red fluorescence. This tissue is fairly easily } \\
\text { eliminated with a manual excavator. } \\
\text { - Abnormal dentin at the end of excavation: light green-grey fluorescence, } \\
\text { sometimes with a very slight pink transparency (Figure 2, arrow) }\end{array}$ \\
\hline & $\begin{array}{l}\text { Clinical considerations: } \\
\text { In case of high caries risk-applicable to all lesion types, active or arrested- } \\
\text { consider the following: } \\
\text { - According to depth of lesion: the residual septicity of the dentinal structure is } \\
\text { the key factor in the general practitioner's thinking. } \\
\text { - Opt for provisional fitting of a conventional glass ionomer cement, such as Fuji } \\
\text { VII (GC, Japan). } \\
\text { - Reduce the caries septicity level by applying the recommendations of the } \\
\text { Cambra concept. } \\
\text { - Perform permanent treatments once the carious disease has stabilized. } .^{1,3,4}\end{array}$ \\
\hline & $\begin{array}{l}\text { Permanent treatments: } \\
\text { In case of low caries risk-applicable to all lesion types, active or arrested-consider } \\
\text { the following: } \\
\text { - Using a dental dam is essential. } \\
\text { - Favor manual excavation over mechanical rotary caries removal. } \\
\text { - Disinfect the dentin wound with a } 5 \% \text { aqueous solution of chlorhexidine. } \\
\text { - If the area is accessible and enables a leak-tight contact, ozone disinfection } \\
\text { therapy is feasible. } \\
\text { - Favor fitting of a bioactive dentin substitute, such as resin-modified glass } \\
\text { ionomer, especially if the enamel edges have disappeared.21 } \\
\text { - In case of a eugenol-based dressing, opt for an amalgam restoration. } \\
\text { - In case of a temporary dentin substitute such as conventional glass ionomer } \\
\text { cement, consider the fitting time and the bonding of the adhesive/composite } \\
\text { system used with this material. } \\
\text { - Consider whether it is necessary to use antiseptic enamel-dentinal adhesives. } \\
\text { structure: destructured tissue, residual minerality, and proximity to pulp. }\end{array}$ \\
\hline \multirow[b]{2}{*}{ Arrested Lesion } & $\begin{array}{l}\text { Visual signals in fluorescent mode: } \\
\text { - Healthy dentin: acid green fluorescence. } \\
\text { - Infected dentin: green-black fluorescence. } \\
\text { - Infected/affected dentin: dark red fluorescence. This tissue is more difficult to } \\
\text { eliminate with a manual excavator. Surgical treatment of this tissue by rotary } \\
\text { milling (tungsten carbide or ceramic) under spray is feasible. } \\
\text { - Abnormal dentin at end of excavation: light green-grey fluorescence, with } \\
\text { systematically persisting shady pink fluorescence at the bottom of the } \\
\text { preparation, opposite the pulpal wall (Figure 4, arrow). }\end{array}$ \\
\hline & $\begin{array}{l}\text { Clinical considerations: } \\
\text { - According to the depth of the lesion: the residual septicity of the dentin } \\
\text { structure and activity of the disease are no longer the key factors in the general } \\
\text { practitioner's thinking. } \\
\text { - Using a dental dam is essential. } \\
\text { - Disinfect the dentin wound with a } 5 \% \text { aqueous solution of chlorhexidine. } \\
\text { - If the area is accessible and enables a leak-tight contact, an ozone disinfection } \\
\text { therapy is feasible. } \\
\text { - Fitting a bioactive dentin substitute such as resin-modified glass ionomer is } \\
\text { balanced with the injection of a chemo-polymerizing composite, especially } \\
\text { if there are persisting enamel edges around the cervical border of the } \\
\text { preparation. } 21 \\
\text { - A lack of residual enamel edges will lead to favoring the use of resin-modified } \\
\text { glass ionomer in this specific case. } 21 \\
\text { - In case of a eugenol-based dressing, opt for an amalgam restoration. } \\
\text { - Temporary fitting of a conventional glass ionomer cement is not absolutely } \\
\text { necessary. } \\
\text { consider the choice of the most appropriate adhesive for the residual dentin } \\
\text { structure: destructured tissue, residual minerality, and proximity to pulp. }\end{array}$ \\
\hline Mixed Lesions & $\begin{array}{l}\text { In case of a mixed lesion (active and arrested), the carious lesion should be } \\
\text { considered active in its entirety. }\end{array}$ \\
\hline
\end{tabular}


Whatever the fluorescence variations, magnification of the carious lesions by a factor of 30 greatly enhanced the clinical decisionmaking process. Even though this aspect was not evaluated during this experiment, a previous study has confirmed the usefulness of the method..$^{20}$ Moreover, because the Sopro imaging ${ }^{\circledR}$ software provides for the recording of the images from the LED camera, further evaluation of acquired images is facilitated by the software.
Tissue discrimination obtained by observable fluorescence variation has become a precious clinical aid that supplements the practitioner's diagnosis capabilities, and has enabled the development of the LIFEDT concept during the preparation phase of treating dental caries. The more than 30x magnification of the image supplements this advantage. Table 1 summarizes the LIFEDT concept in both active and arrested caries processes with the relevant operative
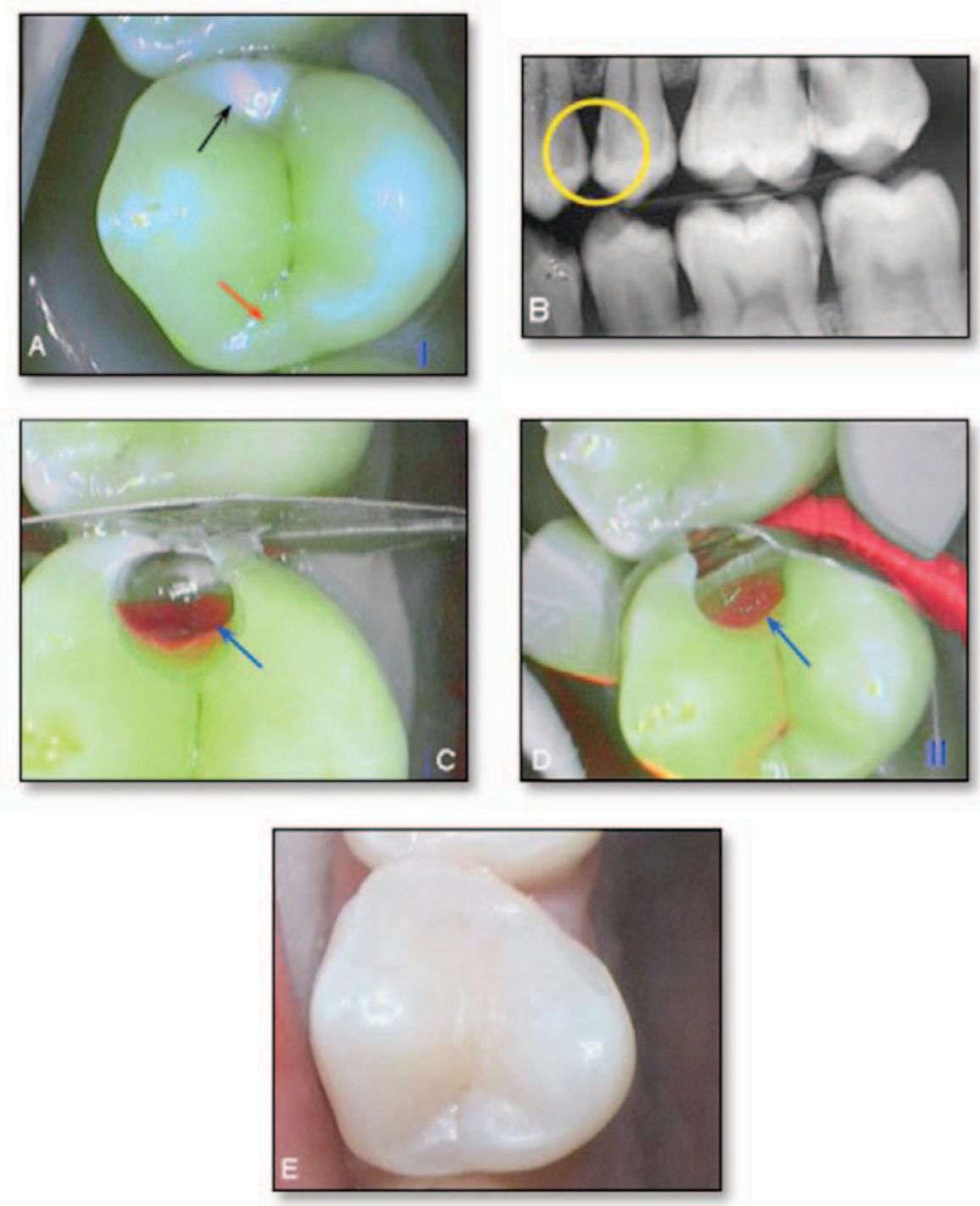

Figure 8. Treatment steps for a carious lesion on the distal aspect of tooth \#24. A. Observation of marginal ridge destructuring in fluorescent mode (black arrow), as opposed to the opposite ridge (red arrow). B. Confirmation of lesion by radiography (yellow circle, distal face of 24). C. Shadowy red lesion, showing the infected/affected interface. D. End of excavation, with persisting sclerotic dentin (shadowy red fluorescence in the bottom, blue arrow), the sign of a slower rather than a quick lesion. The cervical enamel rim has been preserved. E. Completed restoration: Fuji II LC as a dentin substitute, and covered with a nanohybrid composite (Bleach value: $L$ ). 
procedures. The visual examination was performed as shown in Figure 8.

\section{Conclusions}

The potential benefits of the imaging approach used in the present work lie in the guidance of clinical decision making. Prediction of lesion activity in cases of open cavity types of carious lesions is of great interest and may substantially change traditional operative procedures.

Decisions whether to use a bioactive dentin substitute or not could be facilitated. In fact, the bright-red fluorescence of the infected dentin with the intraoral LED camera coincided with the presence of a pale yellow, soft dentin, which is a priori indicative of an active lesion. ${ }^{11}$

Within the limitations of this in vivo study, this new intra-oral LED camera revealed significant variations in fluorescence between sound dentin and active and arrested caries. These findings support the proposed use of the LIFEDT concept as a reasonable clinical protocol for the diagnosis and treatment of dental caries that can be routinely used by clinicians on a daily basis.

\section{Clinical Significance}

The use of a more than 30x magnified image to assess the integrity of tooth structure offers the potential for an improved clinical outcome as a result of a more accurate excavation of carious dentin; all finishing procedures are potentially improved. This clinical concept simplifies the everyday work for general practitioners using a pragmatic approach for treating active and arrested carious lesions by enhancing their diagnostic capabilities and, within the limitations of this concept, facilitates their choice of the restorative materials to be used.

\section{References}

1. Terrer E, Koubi S, Dionne A, Weisrock G, Sarraquigne C, Mazuir A, Tassery H. A New Concept in Restorative Dentistry: Light-Induced Fluorescence Evaluator for Diagnosis and Treatment: Part 1 - Diagnosis and Treatment of Initial Occlusal Caries. J Contemp Dent Pract [Internet]. 2009 Nov;
10(6):086-094. Available from: http://www. thejcdp.com/journal/view/volume10-issue6terrer.

2. Bratthall D, Hänsel Petersson G.

Cariogram - a multifactorial risk assessment model for a multifactorial disease. Community Dent Oral Epidemiol. 2005; 33(4):256-64.

3. Featherstone JDB, Domejean-Orliaguet $S$, Jenson L, Wolff M, Young DA. Caries assessment in practice for age 6 through adult. J Calif Dent Assoc. 2007; 35(10):703-7, 710-3.

4. Jenson L, Budenz AW, Featherstone JD, Ramos-Gomez FJ, Spolsky VW, Young DA. Clinical protocols for caries management by risk assessment. J Calif Dent Assoc. 2007; 35(10):714-23.

5. Lennon AM, Attin T, Buchalla W. Quantity of remaining bacteria and cavity size after excavation with FACE, caries detector dye and conventional excavation in vitro. Oper Dent. 2007; 32(3):236-41.

6. Adeyemi AA, Jarad FD, Pender N, Higham $\mathrm{SM}$. Comparison of quantitative light-induced fluorescence (QLF) and digital imaging applied for the detection and quantification of staining and stain removal on teeth. J Dent. 2006; 34(7):460-6.

7. Rodrigues JA, Hug I, Diniz MB, Lussi A. Performance of fluorescence methods, radiographic examination and ICDAS II on occlusal surfaces in vitro. Caries Res. 2008; 42(4): 297-304.

8. Ismail AI, Sohn W, Tellez M, Amaya A, Sen A, Hasson H, Pitts NB. The International Caries Detection and Assessment System (ICDAS): an integrated system for measuring dental caries. Community Dent Oral Epidemiol. 2007; 35(3):170-8.

9. Hall A, Girkin JM. A review of potential new diagnostic modalities for caries lesions. J Dent Res. 2004; 83 Spec No C:C89-C94.

10. Banerjee A, Watson TF, Kidd EA. Dentine caries: take it or leave it? Dent Update. 2000; 27(6):272-6.

11. Iwami $Y$, Hayashi $N$, Yamamoto $H$, Hayashi $\mathrm{M}$, Takeshige F, Ebisu S. Evaluating the objectivity of caries removal with a caries detector dye using color evaluation and PCR. J Dent. 2007; 35(9):749-54.

12. Christenson $\mathrm{RH}$; Committee on Evidence Based Laboratory Medicine of the International Federation for Clinical Chemistry Laboratory Medicine. Evidence-based 
laboratory medicine-a guide for critical evaluation of in vitro laboratory testing. Ann Clin Biochem. 2007; 44(Pt2):111-30.

13. Forrest JL, Miller SA. Enhancing your practice through evidence-based decision making. J Evid Based Dent Pract 2001; 1(1):51-7.

14. Mount GJ, Tyas, JM, Duke ES, Hume, WR, Lasfargues JJ, Kaleka R. A proposal for a new classification of lesions of exposed tooth surfaces. Int Dent J. 2006; 56(2):82-91.

15. Siegel S, Castellan NL. Nonparametric statistics for the behavioral sciences. 2nd ed.; Singapore: McGraw-Hill; 1998.

16. Kleter GA, Damen JJ, Buijs MJ, Ten Cate $\mathrm{JM}$. Modifications of amino acid residues in carious dentin matrix. J Dent Res. 1998; 77(3):488-95.

17. Lussi A. Comparison of different methods for the diagnosis of fissure caries without cavitation. Caries Res. 1993; 27(5):409-16.

18. Lussi A, Reich E. The influence of toothpastes and prophylaxis pastes on fluorescence measurements for caries detection in vitro. Eur J Oral Sci. 2005; 113(2):141-4.

19. Hamilton JC, Gregory WA, Valentine JB. DIAGNOdent measurements and correlation with the depth and volume of minimally invasive cavity preparations. Oper Dent. 2006; 31(3):291-6.

20. Erten H, Üçtasli MB, Akarslan ZZ, Üzun Ô, Semiz M. Restorative treatment decision making with unaided visual examination, intraoral camera and operating microscope. Oper Dent. 2006; 31(1):55-9.

21. Koubi S, Raskin A, Dejou J, About I, Tassery H, Camps J, Proust JP. Effect of dual cure composite as dentin substitute on marginal integrity of class II open-sandwich restorations. Oper Den. 2009; 34(2):150-6.

\section{About the Authors}

\section{Elodie Terrer, DDS}

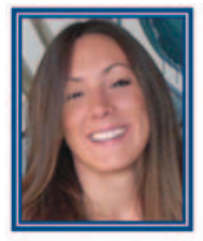

Dr. Terrer is a doctoral student in the Department of Restorative Dentistry of the Marseille Dental School at the University of the Mediterranean. Her major fields of interest are composite restorations and clinical research.

e-mail: elodieterrer83@ hotmail.fr

Anne Raskin, DDS, MS, PhD

Dr. Anne Raskin. DDS, PHD. Department of Biomaterials. IMEB Laboratory. University of Mediterranean. $27 \mathrm{Bd}$ jean Moulin.13355 Marseille. His major fields of interest are bomaterials and clinical research.

e-mail: anne.raskin@univmed.fr

\section{Stephen Koubi, DDS}

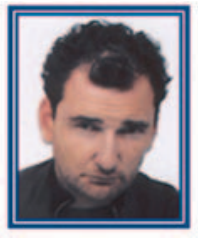

Dr. Koubi is a professor in the Department of Restorative Dentistry of the Marseille Dental School at the University of the Mediterranean. His major fields of interest are composite restorations, clinical research, and prosthetic dentistry.

\section{Alexandro Dionne}

Mr. Dionne is a dental student in the Department of Restorative Dentistry of the Marseille Dental School at the University of the Mediterranean. His major fields of interest are composite restorations and clinical research.

\section{Gauthier Weisrock, DDS}

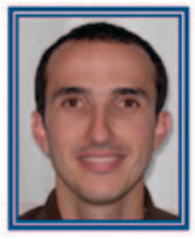

Dr. Weisrock is an assistant professor in the Department of Restorative Dentistry of the Marseille Dental School at the University of the Mediterranean. His major fields of interest are composite restorations and clinical research. 


\section{Caroline Sarraquigne}

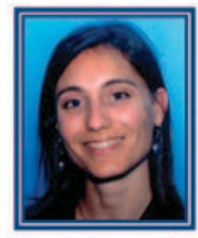

Ms. Sarraquigne is a biomedical engineer in Marseille, France, and a clinical development project manager in dental and medical research. Her major field of interest is to define and create product concepts with the potential of leading to the development of groundbreaking products.

\section{Alain Mazuir}

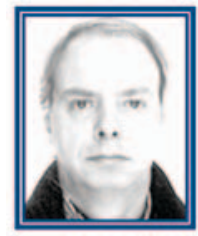

Mr. Mazuir is a biomedical engineer in La Ciotat, France, who is an inventor and patent specialist. His major field of interest is the creation of groundbreaking products associated with dental and medical imagery.

Hervé Tassery, DDS, MS, PhD (Corresponding Author)

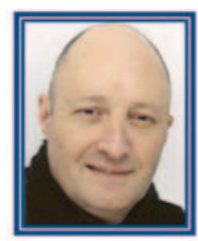

Dr. Tassery is a professor in the Department of Restorative Dentistry of the Marseille Dental School at the University of the Mediterranean. His major fields of interest are clinical research. minimally invasive dentistry and

e-mail: herve.tassery@numericable.fr 